\title{
Effect of cement on the stability and the wearrance of soils in earthworks
}

\author{
BENDIMERAD Karam Feth-Allah ${ }^{1}$, ZADJAOUI Abdeldjalil ${ }^{1}$. \\ ${ }^{1}$ University Abou Bekr Belkaid, Department of civil engineering, Laboratory RisAm, Tlemcen, Algérie.
}

\begin{abstract}
The technique of soil treatment is known for a long time, currently, during the big motorway programs this technique is experiencing important to reach zero imprints and zero deposit in a context of sustainable development or the socio-economic and environmental challenges incite during the work of earthworks. Our work puts highlights the treatment of fine soils in westerns region of Algeria (wilaya of Tlemcen, a project to construct a payment station for the entry of the wilaya (sample $n^{\circ} 1$ ), electrical post 400/200 KVA in the locality Ain Fetah (sample ${ }^{\circ}{ }^{\circ}$ )), belonging to the class $\mathrm{A}_{3 \mathrm{~h}}$ (very plastic clay) according to the Technical Guide for Earthworks (GTR), whose use in the raw state would involve great risks of stability because of their plasticity $(\mathrm{Ip}>20 \%)$ and their low capacity $(\mathrm{CBR}<25)$ according to the Specification of the Algerian Loads, Technical Clauses (CSDCA-CT) by the incorporation of the stabilizing agents, for example the variant of locally manufactured CEM II / A42.5N composite cement, in order to define their behaviours by examining the variation of their characteristics determined according to the Algerian standards and at a ambient temperature according to the additive dosage and to contribute to the deduction of the interest of the method demonstrated previously. The results obtained clearly show a tendency the rearrange classification of the soils studied according to the unified system en proportion whit to the additive dosage ( 0 to $14 \%$ ) in view of the appreciable change in the plasticity behaviour, which results in a decrease in the plasticity index, going up to $37.7 \%$ and the $11 \%$ of the maximum dry density accompanied by a satisfactory increase in the suitability of the materials to be supported a load with different moisture content and changes in water regime exceeds $100 \%$. Given the unavailability of other exploitable deposits near the site and the experimental results obtained, the variant of the treatment seems feasible.
\end{abstract}

KEYWORD: Fine soil, Cement, Soil treatment, Geotechnical, Durability.

\section{Introduction}

During the last two decades, Algeria has experienced a considerable development in its infrastructure, including transport (road, highway and railroad), this progress has highlighted a technicaleconomic and environmental in order to interaction to limit the impact of this progress use exclusively have by the exclusive use of soils located in the land reserve of the earthworks project.

This objective requires the use of soils with insufficient properties, given the geological characteristics of the region of western Algeria that is part of an arid to semi-arid zone delimited by the Tell Atlas at the north and the Saharan Atlas at the south is extended of east at west until to the countries bordering the Maghreb, characterized by a cold and wet winter and a hot and dry summer, the majority of these formations are fine-matrix (clay, silt, marl, etc ...) making subject of several construction problems for a road application and pose a compaction problem in the dry side (difficult or impossible) and the wet side (sticky and expansive on the other hand). [4, 11]

So, in this sense, the improvement of the soils end by the incorporation in situ of the stabilizers (additives), for example, cement, remains one of the potential solutions to achieve this goal.

The first works in this field date back more than fifty years, which developed simultaneously with the knowledges of the mechanical performances of improved soils, their short-term and long-term behavior and interaction between the additive and the fine particles of soils which induces a series of complex physicochemical phenomena with very variable kinetics modifying the characteristics of the soil which results in a modification of water content, density of compaction and their lift. [13]

The present work is intended as an like a experimental contribution in this field at the macroscopic scale, it's about application of this technique to the case 
of thes soils of western Algeria with a goal, zero borrowing, zero deposit and which spread over two parts, the identification and analysis of the influence of the treatment on the physical and mechanical properties of the two soils studied.

\section{Experimental materials and methods}

\subsection{Materials and additives}

The two soils studied in this work were collected from the wilaya of Tlemcen (M1 at the locality of El Koudia, on the other hand M2 of locality Ain Fetah), extract between $1.50 \mathrm{~m}$ and $4.50 \mathrm{~m}$ depth and then transported to the mechanical soil laboratory of the University of Tlemcen.

The different physical and mechanical characteristics of the samples studied were determined in accordance with the Algerian standards (NA) and classified according to the GTR, they are reported in table 1 .

Table 1. Geotechnical characteristics of the samples studied.

\begin{tabular}{|c|c|c|c|}
\hline & Standards & $\mathbf{M}_{1}$ & $\mathbf{M}_{2}$ \\
\hline $\mathrm{D}_{\text {Max }}[\mathrm{mm}]$ & \multirow{3}{*}{$\begin{array}{l}\text { Particle size analysis : } \\
\text { NF P 94-056_NA } 5232 .\end{array}$} & $\leq 50$ & $\leq 50$ \\
\hline$\leq 2 \mathrm{~mm}[\%]$ & & 100 & 85 \\
\hline$\leq 80 \mu \mathrm{m}[\%]$ & & 75 & 70 \\
\hline $\operatorname{Ip}[\%]$ & $\begin{array}{c}\text { Atterberg limits : } \\
\text { NF P 94-052_NA } 16213 .\end{array}$ & 34 & 28 \\
\hline V.B.S. & $\begin{array}{c}\text { Methylene Blue test: } \\
\text { NF P 94-068_NA 5288. }\end{array}$ & 6,15 & 4,50 \\
\hline $\mathrm{W}_{\text {opt }}[\%]$ & \multirow{2}{*}{$\begin{array}{c}\text { PROCTOR test : } \\
\text { NFP P } 94-093_{\text {_ NA } 5262 .}\end{array}$} & 5 & 7 \\
\hline$\rho_{d}\left[t / m^{3}\right]$ & & 1,675 & 1,725 \\
\hline${\mathrm{C} B R_{\text {Immediate }}[\%]}$ & \multirow{2}{*}{$\begin{array}{c}\text { CBR test : } \\
\text { NFP P 94-078_NA } 5252 .\end{array}$} & 12 & 15 \\
\hline $\mathrm{C} B R$ Soaked $[\%]$ & & 7 & 9 \\
\hline \multicolumn{2}{|c|}{ Classification GTR : } & $\mathbf{A}_{3 \mathrm{~h}}$ & $\mathbf{A}_{3 \mathrm{~h}}$ \\
\hline
\end{tabular}

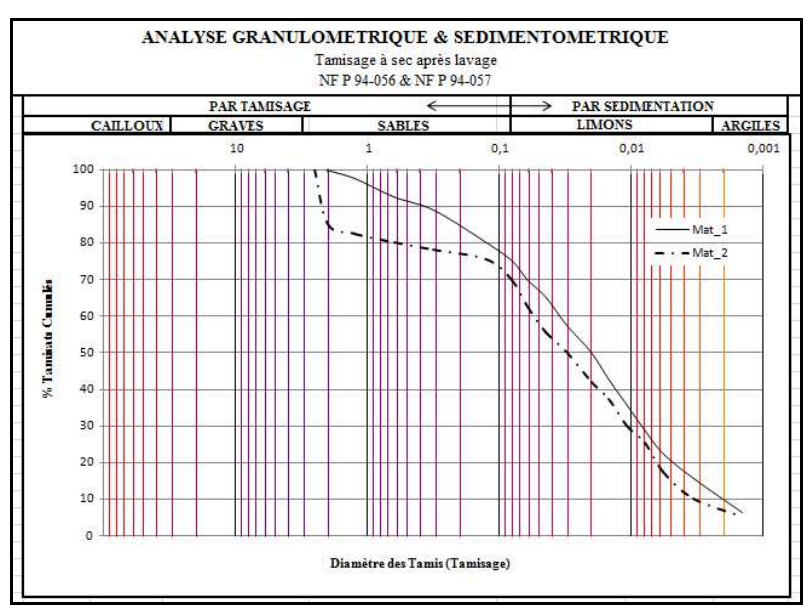

Fig.1. Granulometric curves of the two soils.

The cement used as additive in this study is one of the local products manufactured by the Beni Saf cements company in the western region of Algeria, delivered in a
$50 \mathrm{~kg}$ bag certified according to the Algerian NA 442 standard.

The technical characteristics provided by the manufacturing plant are summarized in the tables below, tables 2 and 3 .

Table 2. Data sheet of cement used.

\begin{tabular}{|l|c|}
\hline Type of cement & CEM II/A-P \\
\hline Resistance class & $\mathbf{4 2 . 5} \mathbf{~ N}$ \\
\hline Clinker Protland (\% by weight) & $\mathbf{8 0 ~ - 9 4}$ \\
\hline Secondary constituents__ P (\% by mass) & $\mathbf{6 ~ - ~ 2 0}$ \\
\hline
\end{tabular}

Table 3. Physico-chemical characteristics of cement.

\begin{tabular}{|l|c|}
\hline Sulphate content $[\%]\left(\mathrm{SO}_{3}\right)$ & $\leq \mathbf{3 . 5} \%$ \\
\hline Magnesium oxide content $[\%](\mathrm{MgO})$ & $\leq \mathbf{5 . 0} \%$ \\
\hline Start of taking $[\mathrm{min}]$ & $\mathbf{T} \geq \mathbf{6 0 . 0}$ \\
\hline Compressive strength at 2 days $[\mathrm{MPa}]$ & $\mathbf{L i} \leq \mathbf{1 2 . 5}$ \\
\hline Compressive strength at 28 days $[\mathrm{MPa}]$ & $\mathbf{L i} \leq \mathbf{4 2 . 5}$ \\
\hline
\end{tabular}

\subsection{Methods}

In order to appreciate the variations of the geotechnical characteristics of the samples studied during their interaction with the additive (cement) and in addition to the identification tests, an experimental program was developed in place such as : classical density tests (Proctor compaction ), plasticity (Atterberg limits) and immediate and impregnated California Bearing Ratio (CBR), carried out on untreated samples (controls) and on treated samples with various cement content according to the schedule summarized in table 4 . [5-10]

Table 4. Different combinations.

\begin{tabular}{|c|c|c|c|c|c|}
\hline- & \% Mat. & \% Ciment & - & \% Mat. & \% Ciment \\
\hline $\mathbf{1}$ & 100 & 0 & $\mathbf{7}$ & 90 & 10 \\
\hline $\mathbf{2}$ & 98 & 2 & $\mathbf{8}$ & 89 & 11 \\
\hline $\mathbf{3}$ & 96 & 4 & $\mathbf{9}$ & 88 & 12 \\
\hline $\mathbf{4}$ & 94 & 6 & $\mathbf{1 0}$ & 87 & 13 \\
\hline $\mathbf{5}$ & 92 & 8 & $\mathbf{1 1}$ & 86 & 14 \\
\hline $\mathbf{6}$ & 91 & 9 & \multicolumn{4}{|l}{} \\
\cline { 1 - 4 } & & &
\end{tabular}

\subsubsection{Sample preparation}

After the extraction of the samples, put them in an oven for 24 hours at a temperature of $105^{\circ} \mathrm{C}$ in order to eliminate all traces of moisture, it was then proceeded to their grinding and then to the dry sieving to have a very fine grind.

The cement in turn, went through dry sieving to avoid lumps. 
Of the soil and additive quantities were weighed and dry blended according to the combinations mentioned above and stored in dry places to avoid tjeir humidification. [4, 12]

\section{Results and discussions}

\subsection{Results}

The following figures from 2 to 6 show the effect of the cement on the clay content, the compaction content, the dry density and the strength of the two materials studied.

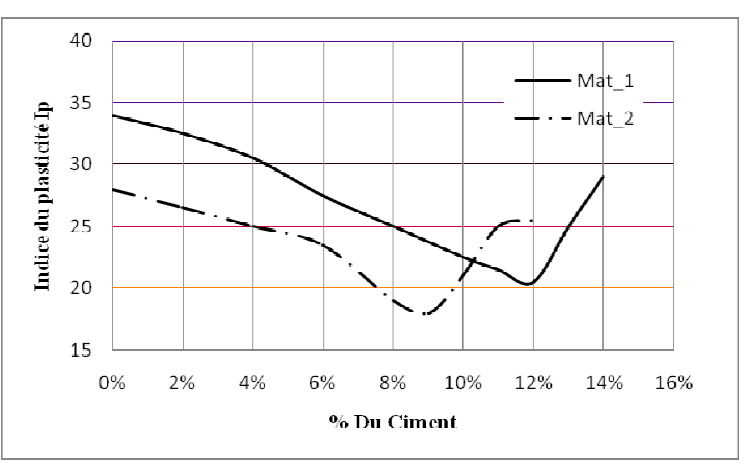

Fig.2. Effect of cement on plasticity.

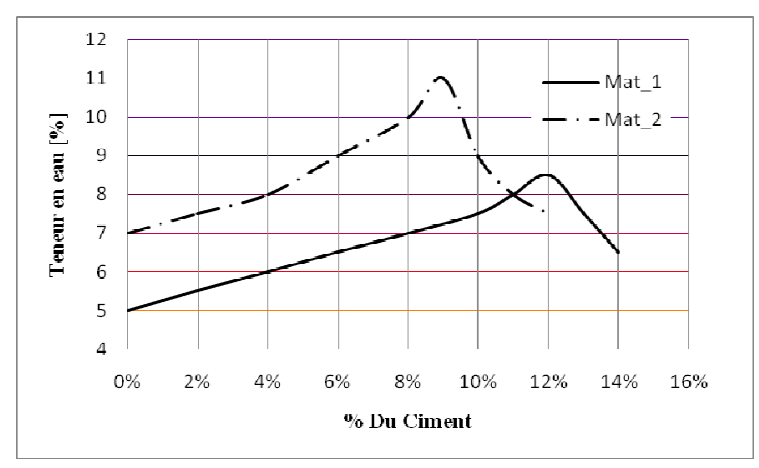

Fig.3. Effect of cement on compaction water content.

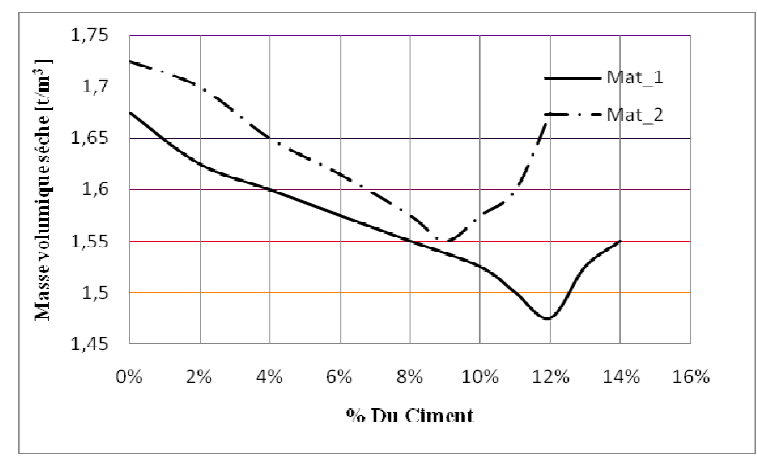

Fig.4. Effect of cement on dry density.

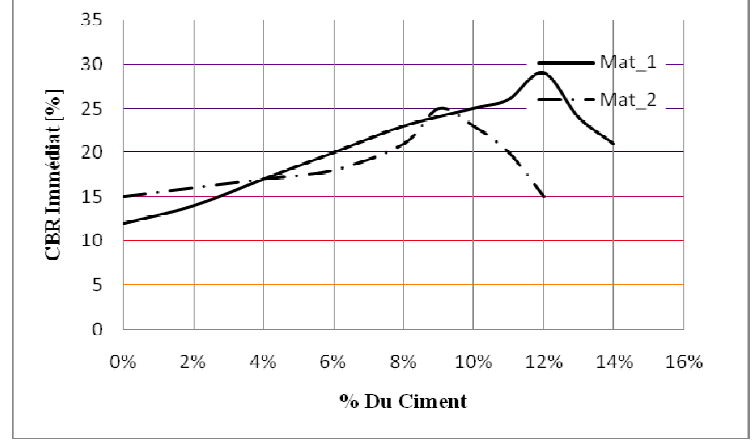

Fig.5. Effect of cement on resistance "CBR Immediate".

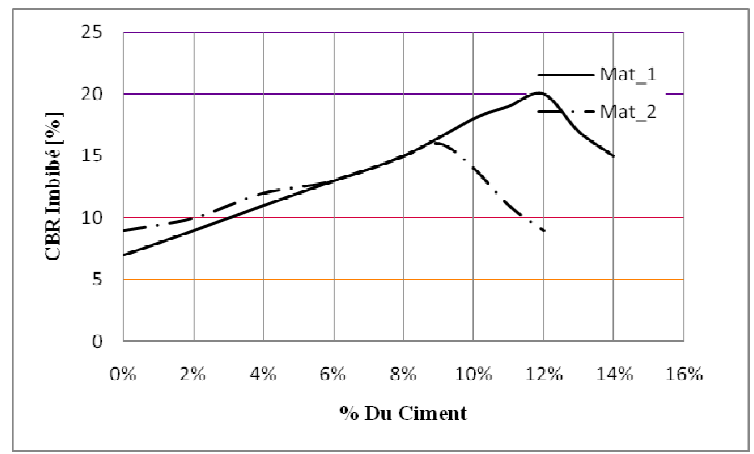

Fig.6. Effect of cement on resistance "CBR Soaked".

\subsection{Discussions}

The figures above show the results of the tests carried out on the two materials, from where a reshuffling of the geotechnical characteristics is clearly observed in the short term in proportionality with the cement dosage until the opposite effect on the characteristics of compaction ( increase in the water content and a lowering in dry density of about $11 \%$ ), of plasticity (a decrease going up to $37.7 \%$ of the plasticity index by aport to its natural state) and the wearrance (an indisputably improvement in CBR indices exceeding thes $100 \%$ at various water regimes).

These variations are consistent with the results of several researchers working on different types of soils that can be explained by a series of physico-chemical phenomena with very variable kinetics from the moment of the addition of the additive in the presence of water :

1. Hydration of cement defined as an exothermic reaction that leads to a reduction of the soil water content, concomitantly the variation of plasticity.

$$
\begin{aligned}
& \mathrm{CaO}+\mathrm{H}_{2} \mathrm{O} \rightarrow \mathrm{Ca}(\mathrm{OH})_{2}+\text { Chaleur }(15.5 \mathrm{kcal} / \mathrm{mol} \mathrm{CaO}) \\
& \mathrm{Ca}(\mathrm{OH})_{2} \rightarrow \mathrm{Ca}^{2+}+2 \mathrm{OH}^{-}
\end{aligned}
$$

2. Agglomerations of the elementary elements of the soil (flocculation of the clay particles) due to the cation exchange capacity of the clays to fixed the calcium ions $\mathrm{Ca}^{2+}$ released during the additive 
addition and leads to a modification of the characteristics of the compaction.

3. Pozzolanic reactions (with a more or less slow kinetics) due to the saturation of the minerals in calcium to train of the new hydrates, such as hydrated calcium silicate (CSH), which initiates a second phase in the development of mechanical performances (the bearing of the soil).

These processes are conditioned by the proportion, morphology, specific surface and the cationic exchange capacity of the clay minerals in the soils under study. [112]

\section{Conclusions}

The results obtained in this study give a practical insight into the chemical treatment of soils saw a road application and constitute a important asset when earthworks are being carried out, or the use of cement as a stabilizing material seems to be one of the many methods available allow a durable, stable and economical construction of embankments and layers of form presenting satisfactory characteristics only by using the materials located in the land reserve of the project thanks to the facility of adaptation to the constraints of exploitations and implementation despite the complexity of mechanisms reactions during in the additive soil interaction, what might seem surprising for research that wants to be applied by simple field and laboratory tests, needs precise and rigorous control.

\section{Bibliographical references}

1. N. Cabane, Sols traités à la chaux et aux liants hydrauliques (Université de Jean Monnet, 2005).

2. V. Ferber, Sensibilité des sols fins compactés à l'humidification (Université de Nantes, 2005).

3. L. Saussye, Traitement des sols aux liants hydrauliques (Université de Caen Basse Normandie, 2012).

4. W. Khebizi, Etude de la durabilité des sols argileux améliorés avec des ajouts minéraux (Université de Chlef, 2011).

5. A. Al-taim, M. Disfani, R. Evans, Procedia engineering J. E. 143, 615-622 (2016).

6. D. Ribeiro, R. Néri, R. Cardoso, Procedia engineering J. E. 143, 59-66 (2016).

7. M.A. Ozdemir, Procedia engineering J. E. 143, 498505 (2016).

8. G. F. Bell, Engineering geology J. E. 42, 223-237 (1996).

9. O. Cuisinier, A. Jean-Claude, D. Dimitri, Engineering geology J. E. 123, 187-193 (2011).

10. L. Saussaye, M. Boutouil, F. Baraud, L. Leleyter, Engineering geology J. E. 189, 89-103 (2015).

11. A. Mhamedi, M. Khemissa, HBRC J. E. 11, 82-90 (2015).

12. G. Geoffrey, H. Schad, Otto-Grah Journal J. E. 11, (2000). 